\title{
Physiology and consequences of lung hyperinflation in COPD
}

\author{
D.E. O'Donnell and P. Laveneziana
}

\begin{abstract}
Lung hyperinflation commonly accompanies expiratory flow limitation in patients with chronic obstructive pulmonary disease (COPD) and contributes importantly to morbidity and an impoverished quality of life. It is not surprising, therefore, that lung hyperinflation has become an important therapeutic target in symptomatic COPD patients. Acute dynamic increases in lung hyperinflation under conditions of worsening expiratory flow limitation and increased ventilatory demand (or both) can seriously stress cardiopulmonary reserves in patients with more advanced disease. The present understanding of the physiological mechanisms of dynamic hyperinflation during exacerbations of COPD and during physical activity continues to grow, together with an appreciation of its negative mechanical and sensory consequences. In this brief overview, definitions and measurement of lung hyperinflation during rest and exercise will be discussed and its potential clinical importance will be considered. The focus will mainly be on current concepts of the mechanisms of air trapping and its role in inducing respiratory discomfort and activity limitation in COPD.
\end{abstract}

KEYWORDS: Chronic obstructive pulmonary disease, dynamic hyperinflation, dyspnoea, exercise, lung volume, respiratory mechanics

E xpiratory flow limitation (EFL) is the pathophysiological hallmark of chronic obstructive pulmonary disease (COPD) and arises because of the dual effects of permanent parenchymal destruction (emphysema) and airway dysfunction, which in turn reflect the effects of small airway inflammation (mucosal oedema, airway remodelling and mucous impaction) and possibly increased cholinergic airway smooth muscle tone (fig. 1). Emphysema results in reduced lung elastic recoil pressure, which leads to a reduced driving pressure for expiratory flow through narrowed and poorly supported airways in which airflow resistance is significantly increased. EFL is said to be present "when the expiratory flows generated during spontaneous tidal breathing represent the maximal possible flow rates that can be generated at that operating lung volume" [2]. Under conditions of EFL, expiratory flow rates are independent of expiratory muscle effort and are determined by the static lung recoil pressure and the resistance of the airways upstream from the flow-limiting segment $[2,3]$.

In health, the relaxation volume $(V r)$ of the respiratory system is dictated by the balance of forces between the inward elastic recoil pressure of the lung and the outward recoil pressure of the chest wall. With advancing age, changes in the connective tissue matrix of the lung result in a reduction of the lung elastic recoil pressure, and the equilibrium point (where the net elastic recoil of the total respiratory system is zero) therefore occurs at a higher lung volume than in youth [4]. In COPD, the increased compliance of the lung, as a result of destructive emphysema, leads to a re-setting of the respiratory system's relaxation volume to a higher level than in age-matched healthy individuals (fig. 2) [5]. This has been termed "static" lung hyperinflation.

\section{RESTING LUNG HYPERINFLATION} the end of spontaneous expiration (i.e. endexpiratory lung volume (EELV)) is increased in COPD compared with health. EELV is synonymous with the more conventional term "functional residual capacity". While in health the EELV during relaxed breathing at rest corresponds with the actual equilibrium position of the respiratory system, this is often not the case in COPD [5]. During spontaneous resting breathing in patients with EFL, EELV is also "dynamically" determined and is maintained at a level above the statically determined $V \mathrm{r}$ of the respiratory system. In flow-limited patients, the mechanical time constant for lung emptying (i.e. the product of compliance and resistance $(\tau))$ is increased in many alveolar units, but the expiratory time
The volume of air remaining in the lung at

\section{AFFILIATIONS}

Division of Respiratory and Critica Care Medicine, Dept of Medicine, Queen's University, Kingston, ON, Canada.

\section{CORRESPONDENCE}

D.E. O'Donnell

102 Stuart Street Kingston

ON

Canada K7L 2V6

Fax: 16135491459

E-mail: odonnell@post.queensu.ca 
available (as dictated by the respiratory control centres) is often insufficient to allow EELV to decline to its normal $V \mathrm{r}$, and gas accumulation and retention (often termed "air trapping") results. In other words, lung emptying during expiration becomes incomplete because it is interrupted by the next inspiration, and EELV therefore exceeds the natural $V \mathrm{r}$ of the respiratory system. EELV in COPD is a continuous dynamic variable that varies with the extent of EFL and time-constant abnormalities and the breathing pattern for a given ventilation, as expressed by the following equation [6]:

$$
\text { EELV-Vr }=V \mathrm{~T} /\left(\mathrm{e}^{\mathrm{T}_{\mathrm{e}}} / \tau_{\mathrm{rs}}-1\right)
$$

where $T \mathrm{e}$ is expiratory time, $\tau \mathrm{rs}$ is time constant for emptying of the respiratory system, $V \mathrm{~T}$ is tidal volume and base $\mathrm{e}$ is 2.718282

In patients with diffuse bronchoconstriction and EFL, severe lung hyperinflation is best explained by dynamic rather than static mechanisms [7-10]. The role of other potential contributors to lung hyperinflation, such as re-setting of the passive elastic properties of the chest wall or active inspiratory

a)

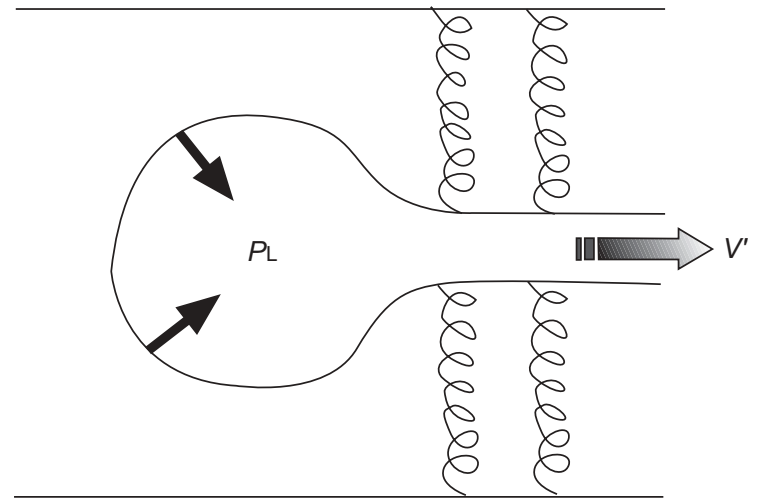

c)

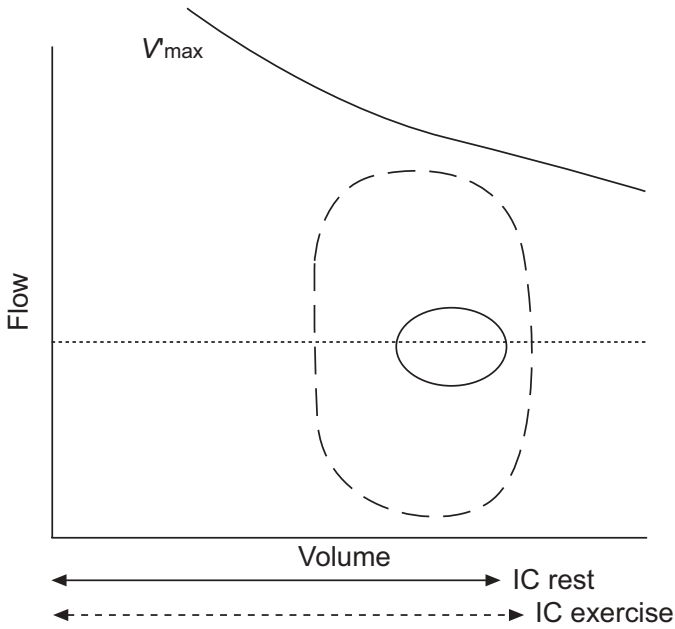

muscle and laryngeal braking during expiration, remains uncertain in COPD [11-13].

\section{CLINICAL EXAMPLES OF DYNAMIC HYPERINFLATION IN COPD}

During acute exacerbations of COPD, EFL is increased (which affects the time constant of the respiratory system) and ventilatory demand and breathing frequency may also be increased (reflecting increased ventilation/perfusion $\left(V^{\prime} / Q^{\prime}\right)$ ratio abnormalities). Together, these result in acute dynamic hyperinflation $(\mathrm{DH})$, which is defined as a temporary and variable increase in EELV above its baseline value. In other studies and work by one of the present authors, it has recently been argued that acute $\mathrm{DH}$ in the setting of exacerbations contributes importantly to their most prominent symptom, i.e. worsening dyspnoea [14-16]. Under any condition of increased ventilation in flow-limited patients with COPD (i.e. exercise, voluntary hyperventilation, anxiety, transient hypoxaemia), inspiratory tidal volume increases and expiratory time diminishes further as breathing frequency increases above the baseline value, causing further acute-on-chronic DH [15-19].

b)

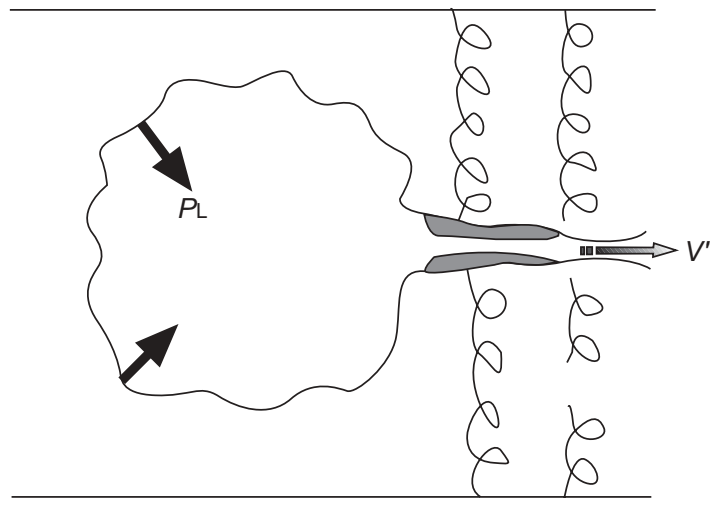

d)

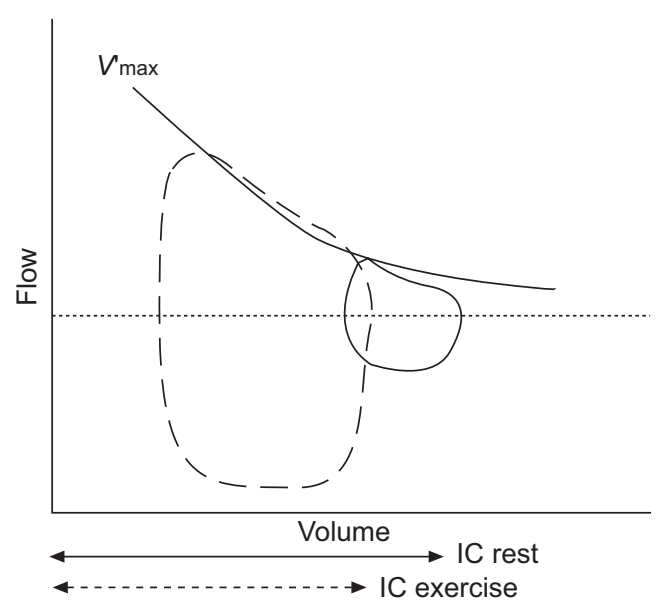

FIGURE 1. Schematic representations of alveolar units a) in health and b) in chronic obstructive pulmonary disease (COPD), and their corresponding flow versus volume profiles in c) health and d) COPD. In COPD, expiratory flow limitation (EFL) occurs because of the combined effects of increased airway resistance and reduced lung recoil: alveolar emptying is therefore critically dependent on expiratory time, which, if insufficiently long, results in lung over-inflation (reduction in inspiratory capacity (IC)). The presence of EFL is suggested in COPD by the encroachment of tidal expiratory flows on the forced maximal expiratory flow envelope over the tidal operating lung volume range. In contrast to health, hyperinflation occurs in COPD during exercise, as indicated by the shift in end-expiratory lung volume to the left, i.e. reduced IC. PL: lung recoil pressure; $V^{\prime}$ : gas flow; $V^{\prime}$ max: maximal expiratory flow. Solid, circular lines: tidal volume at rest; dashed, circular lines: tidal volume during exercise. Reproduced and modified from [1], with permission from the publisher. 
a)

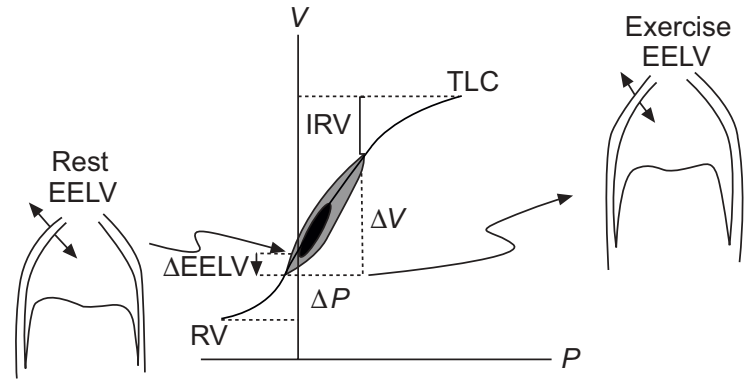

b)

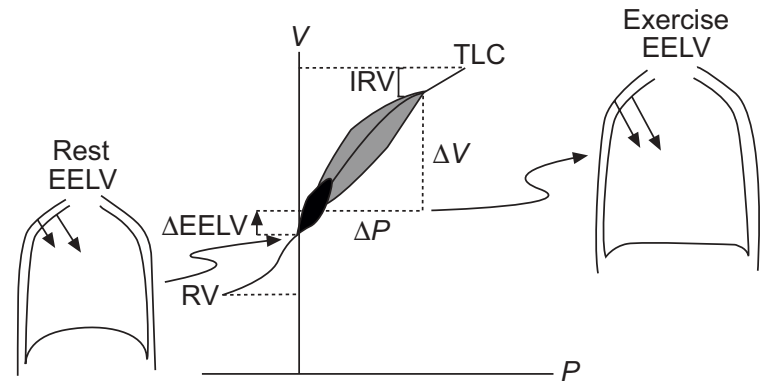

FIGURE 2. Pressure $(P)$-volume $(V)$ relationships of the total respiratory system a) in normal and $b$ ) in chronic obstructive pulmonary disease (COPD). Tidal $P-V$ curves during rest ( $\square$ ) and exercise ( $\square$ ) are shown. In COPD, because of resting and dynamic hyperinflation (a further increased end-expiratory lung volume $(E E L V)$ ), exercise tidal volume (VT) encroaches on the upper, alinear extreme of the respiratory system's $P-V$ curve where there is increased elastic loading. In COPD, the ability to further expand $V_{T}$ is reduced, i.e. inspiratory reserve volume (IRV) is diminished. In contrast to health, the combined recoil pressure of the lungs and chest wall in hyperinflated patients with COPD is inwardly directed during both rest and exercise; this results in an inspiratory threshold load on the inspiratory muscles. RV: residual volume; TLC: total lung capacity.

\section{DETECTION, MEASUREMENT AND DEFINITIONS OF LUNG HYPERINFLATION}

Lung hyperinflation is present when gas volume in the lungs, or in a region of the lung, is increased compared with the predicted value. Thoracic hyperinflation in patients with COPD can be detected by physical examination. Recognised clinical features of severe hyperinflation include the inward motion of the lower lateral ribcage during inspiration, as originally described by STOKЕS [20], and paradoxical inward motion of the anterior abdominal wall in synchrony with inspiratory flow [21, 22]. Hyperinflation in its earlier stages is often underestimated, even after assiduous clinical assessment. Lung hyperinflation can be detected and measured by a variety of radiographic techniques [23-27]. However, the methodology for radiographic lung volume measurement is not standardised and is rarely used in clinical practice for quantitative purposes. High-resolution computed tomography scanning has confirmed that airspace dilatation can be either regionally localised or homogeneously distributed throughout both lungs [26, 27]. The extent and distribution of airspace dilatation within the lungs may have important physiological and clinical implications that are currently being studied.

Body plethysmography remains the gold standard for the measurement of EELV and has been shown to be reliable. Inert gas dilution techniques are also used extensively to measure hyperinflation but may underestimate absolute lung volumes because of the effect of noncommunicating airways. Subtraction of lung volumes derived by dilutional techniques from those that are plethysmographically derived provides an estimate of noncommunicating (or trapped) gas in the lung.

Conventionally, lung hyperinflation is said to exist when the total lung capacity (TLC) is $>120 \%$ of the predicted value. Marked elevation of the TLC usually means that increased lung compliance, as a result of emphysema, is a primary determinant of lung hyperinflation. Hyperinflation of other volume compartments (i.e. residual volume (RV) or EELV) is usually increased in the setting of an elevated TLC. However, increased EELV and RV are often present in the setting of preserved, or slightly elevated, TLC. In such circumstances, particularly with large elevations of these volume compartments, dynamic mechanisms are likely to be instrumental. Thus, the increase in RV in COPD may reflect reduced duration of the forced expiratory manoeuvre because of the development of intolerable respiratory discomfort [10]. Gas compression effects and, possibly, negative effort dependence may also contribute to an increased RV in flow-limited patients [10]. As already mentioned, the increased EELV in flowlimited patients is often dynamically determined. Lung hyperinflation is present if measurements of EELV, RV or $\mathrm{RV} / \mathrm{TLC}$ are above the upper limits of natural variability. In practice, values exceeding $120-130 \%$ pred are deemed to be potentially clinically important, but these "cut-offs" remain arbitrary. No standardised stratification system currently exists for assessment of severity of hyperinflation. In the absence of any consensus on the definition or severity of hyperinflation, when using the term, the volume compartment referred to (i.e. TLC, EELV, RV) and the method used in measurement should be specified and the value should be expressed as $\%$ pred $[28,29]$.

The natural history of the development of lung hyperinflation in COPD patients is unknown but clinical experience indicates that this is an insidious process that occurs over decades. It would appear that RV is the first volume component to increase, reflecting increased airway closure. EELV increases thereafter, reflecting the effects of EFL and alteration in static mechanics, and eventually TLC increases as lung compliance increases. However, it is likely that the time course of change in the various volume compartments is highly variable among patients and, in this respect, the impact of the frequency and severity of exacerbations may be important.

Indirect, spirometrically derived assessments of lung hyperinflation are more difficult to interpret (i.e. vital capacity and inspiratory capacity (IC)), particularly in the absence of simultaneous TLC measurements, to rule out a concomitant restrictive ventilatory deficit. Slow vital capacity is less prone to measurement artefact in COPD than the forced vital capacity (FVC) and therefore provides a better estimation of the efficacy of lung emptying [10]. A reduced resting IC can indicate the presence of lung hyperinflation in the setting of EFL [30]. The resting IC represents the operating limits for tidal volume expansion during the increased ventilation of exercise and can predict the peak symptom-limited oxygen uptake in patients with resting EFL [17, 31]. Moreover, a severely reduced IC/ TLC ratio has recently been shown to be an independent 
predictor of poor survival in COPD [32]. In flow-limited patients, the smaller the IC, the closer the operating tidal volume is to TLC and the upper reaches of the respiratory system's flattened pressure-volume relationship. In this respect, the IC is a crude surrogate for the extent of elastic loading. However, the IC remains remarkably preserved in many patients with severe lung hyperinflation, since TLC and EELV can rise in parallel [33-36]. Clearly, in such circumstances, and in the setting of concomitant mechanical restriction or significant inspiratory muscle weakness, the IC alone is not a reliable marker of lung hyperinflation per se.

\section{MEASURING DH}

The rate and magnitude of $\mathrm{DH}$ during exercise is generally measured in the laboratory setting using serial IC measurements [33-36]. Changes in EELV during exercise can also be tracked with newer methods, such as optoelectronic plethysmography or respiratory inductance plethysmography $[37,38]$. The IC is the maximal volume of air that can be inhaled after a spontaneous expiration to EELV. Since TLC does not change during activity $[39,40]$, the change (reduction) in IC reflects the change (increase) in dynamic EELV, or the extent of DH. This simple method has been shown to be reliable and recent multicentre clinical trials have confirmed its reproducibility and responsiveness [33, 34]. In several studies conducted in $>500$ patients with moderate-to-severe COPD, the change in EELV during cycle ergometry averaged $0.4 \mathrm{~L}$ or $\sim 20 \%$ of the resting value with wide variation in the range $[17,35,36]$. Of this population sample, $>80 \%$ showed increases in EELV from rest to peak exercise, confirming the presence of significant $\mathrm{DH}$ (figs 3 and 4) $[17,35,36]$. The minority of patients who showed little reduction in IC with exercise demonstrated the most severe resting lung hyperinflation [17]. The rate of rise of $\mathrm{DH}$ was steeper in patients with the most severe EFL (as measured by the forced expiratory volume in one second/FVC ratio), the

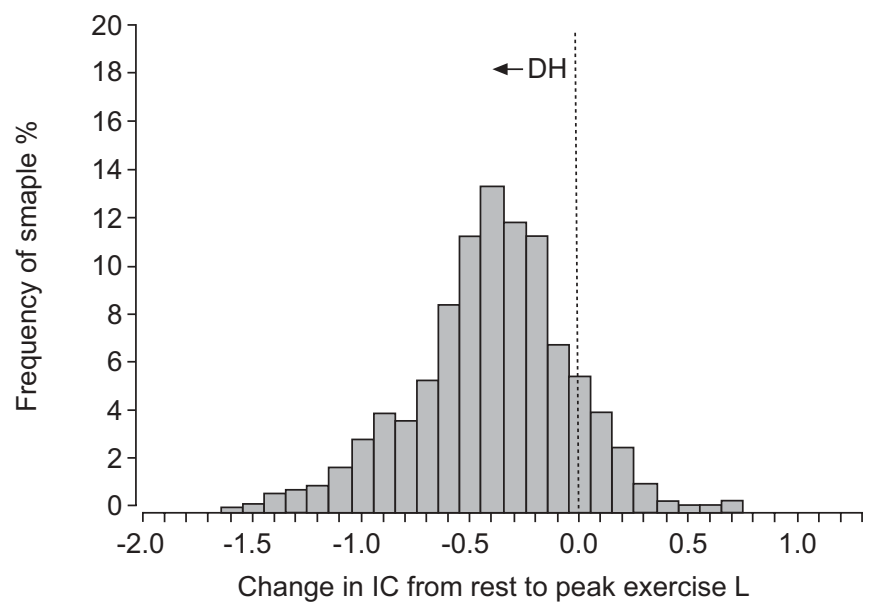

FIGURE 3. The distribution of the extent of change in inspiratory capacity (IC) during exercise is shown in moderate-to-severe chronic obstructive pulmonary disease (COPD; $n=534$ ). A reduction (negative change, i.e. from the dotted zero line to -2.0 ) in IC reflects dynamic hyperinflation (DH) during exercise. Each bar width corresponds to a change in $\mathrm{IC}$ range of $0.10 \mathrm{~L}$. The majority of patients with COPD experienced significant DH during exercise. Graph represents cumulative data taken from references [17, 35, 36]. Reproduced from [41], with permission from the publisher. lowest diffusing capacity for carbon monoxide and the highest ventilatory demand (reflecting greater $V^{\prime} / Q^{\prime}$ abnormalities), and generally reaches a maximal value early in exercise [17].

\section{CONSEQUENCES OF ACUTE DH}

The insidious development of flow limitation and hyperinflation over many years allows for several adaptive mechanisms to come into play to preserve the functional strength of the overburdened inspiratory muscles, particularly the diaphragm [42]. A number of studies have shown several structural adaptations to chronic intrinsic mechanical loading, which include the following: 1) reduction in sarcomere length, which improves the ability of the muscle to generate force at higher lung volumes [43]; 2) an increase in the relative proportion of type I fibres, which are slow-twitch and fatigue resistant [44, 45]; and 3) an increase in mitochondrial concentration and efficiency of the electron transport chain, which improves oxidative capacity [43]. It is believed that the function of
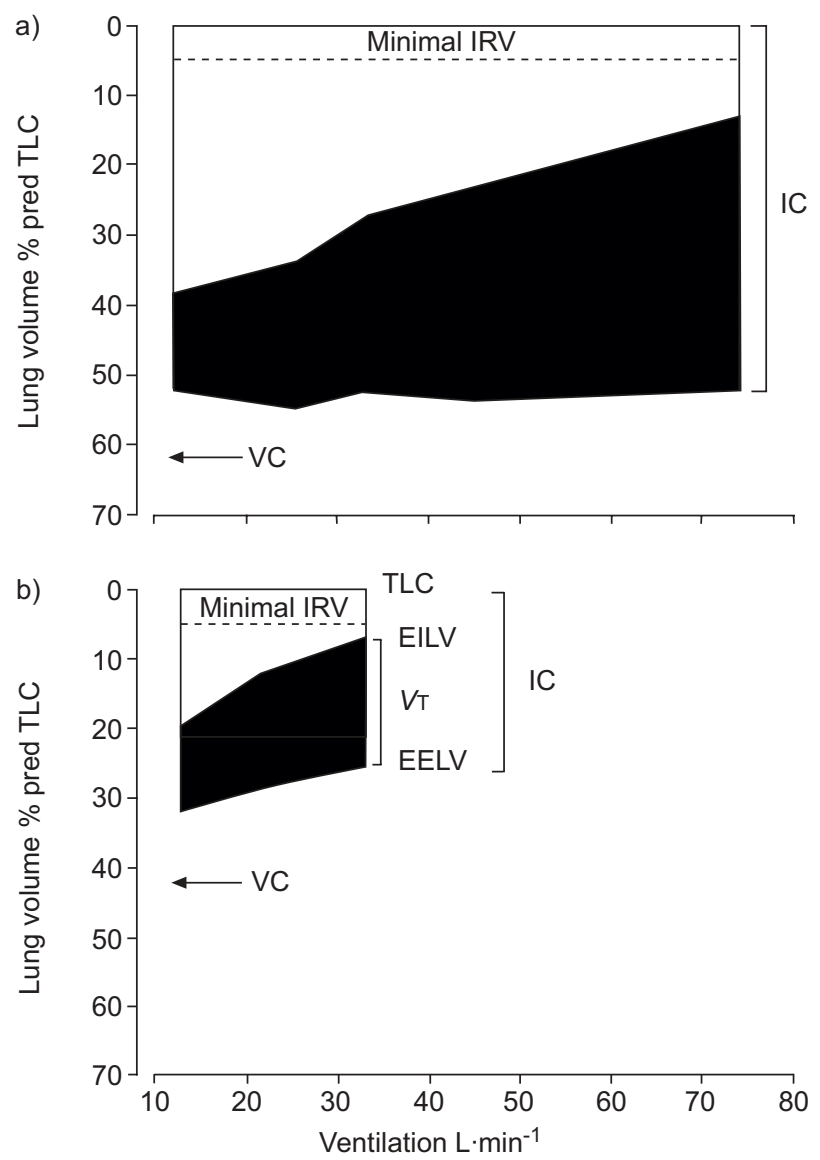

FIGURE 4. Changes in operating lung volumes are shown as ventilation increases with exercise in a) age-matched normal subjects $(n=25)$ and b) chronic obstructive pulmonary disease (COPD; $n=105$ ). "Restrictive" constraints on tidal volume (VT; $\mathbf{- 1})$ expansion during exercise are significantly greater in the COPD group from both below (reduced inspiratory capacity (IC)) and above (minimal inspiratory reserve volume (minimal IRV). $\square$ : IRV. In normal subjects, vital capacity (VC) occurred at $62 \%$ predicted and in COPD patients it occurred at $42 \%$ pred. EELV: end-expiratory lung volume; EILV: end-inspiratory lung volume; TLC: total lung capacity. Reproduced and modified from reference [17], with permission from the publisher. 


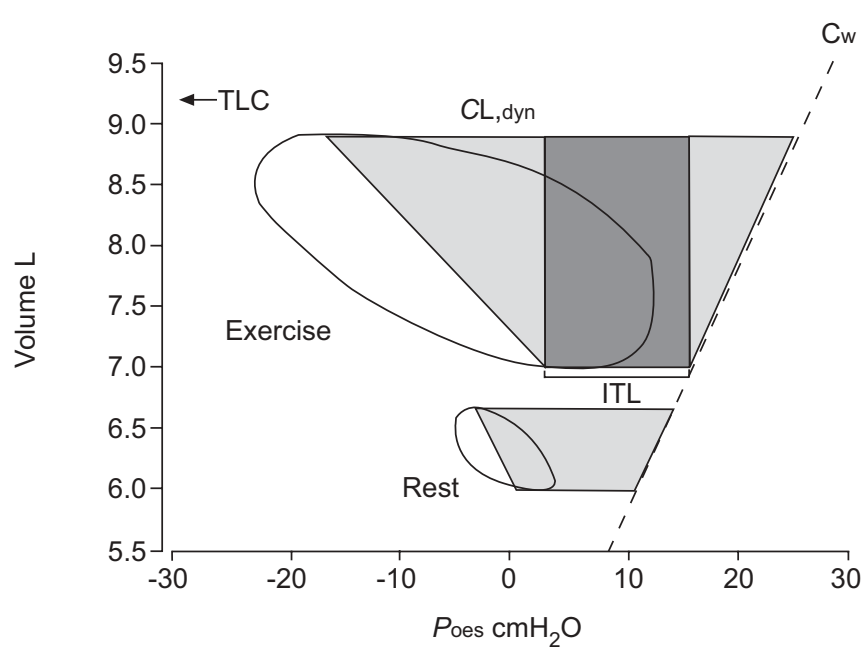

FIGURE 5. Tidal pressure-volume loops (i.e. Campbell diagrams) during rest and exercise in a patient with very severe chronic obstructive pulmonary disease. Note the increased elastic ( $\square$ ) and inspiratory threshold loads (ITL; $\square$ ) resulting from dynamic hyperinflation (change in inspiratory capacity $(\Delta \mid C)$ ). Total lung capacity (TLC) occurred at $9.25 \mathrm{~L}$. CL,dyn: dynamic lung compliance; $\mathrm{Cw}_{w}$ : chest wall compliance; Poes: oesophageal pressure.

intercostal and sternomastoid muscles are at less of a disadvantage than the diaphragm in the presence of severe lung hyperinflation [7]. However, despite this temporal adaptation, the presence of severe hyperinflation means that the ability to increase ventilation when the demand arises is greatly limited in COPD.

The negative effects of acute DH during exercise are now well established and are as follows [46]. 1) DH leads to sudden increases in the elastic and threshold loads on the inspiratory muscles, thus increasing the work and oxygen cost of breathing. In moderate-to-severe COPD, the inspiratory muscle threshold load at the peak of exercise can be considerable (fig. 5) [47]. 2) $\mathrm{DH}$ results in functional inspiratory muscle weakness by maximally shortening the muscle fibres in the diaphragm [48]. 3) $\mathrm{DH}$ reduces the ability of tidal volume to expand appropriately during exercise and this leads to early mechanical limitation of ventilation [49]. 4) In some patients, this mechanical constraint on tidal volume expansion, in the setting of severe $V^{\prime} / Q^{\prime}$ abnormalities (i.e. high fixed physiological dead space), leads to carbon dioxide retention and arterial oxygen desaturation during exercise [49]. 5) Finally, DH adversely affects dynamic cardiac function. [50-52]. All of the above factors are clearly interdependent and contribute in a complex, integrated manner to dyspnoea and exercise limitation in COPD.

A recent mechanistic study in the present authors' laboratory has determined that $\mathrm{DH}$ early in exercise allows flow-limited patients to increase ventilation while minimising respiratory discomfort [53]. Thus, as a result of DH early in exercise, the airways are maximally stretched at the higher lung volumes (close to TLC) and EFL is attenuated, allowing patients to maximise expiratory flow rates. However, this advantage is quickly negated when tidal volume expands to reach a critically low inspiratory reserve volume (IRV) of $\sim 0.5 \mathrm{~L}$ (or
$10 \%$ pred TLC) below TLC. At this "threshold", tidal volume becomes fixed on the upper less compliant extreme of the respiratory system's sigmoid-shaped pressure-volume relationship, where there is increased elastic loading of the inspiratory muscles. At this operating volume, the diaphragm muscle fibres are maximally shortened and the increased breathing frequency leads to significant reductions in dynamic lung compliance. After reaching this minimal IRV, dyspnoea (described as inspiratory difficulty) soon rises to intolerable levels and reflects the widening disparity between inspiratory effort (and central neural drive) and the simultaneous tidal volume response, which becomes essentially fixed, i.e. increased effort/displacement ratio [17, 53]. Dyspnoea intensity correlates well with the increase in this effort/displacement ratio during exercise in COPD $[17,53]$.

The contention that dynamic hyperinflation contributes importantly to exercise limitation in chronic obstructive pulmonary disease has been bolstered by studies that have shown that pharmacological and surgical lung volume reduction are associated with consistent improvements in dyspnoea and exercise endurance.

\section{REFERENCES}

1 O'Donnell DE, Webb KA. Mechanisms of dyspnea in COPD. In: Mahler DA, O'Donnell DE, eds. Dyspnea: Mechanisms, Measurement, and Management. 2nd Edn. New York, Taylor \& Francis, 2005; pp. 29-58.

2 Hyatt RE. Expiratory flow limitation. J Appl Physiol 1983; 55: 1-8.

3 Dawson SV, Elliott EA. Wave-speed limitation on expiratory flow - a unifying concept. J Appl Physiol 1977; 43: 498-515.

4 Pride NB. Ageing and changes in lung mechanics. Eur Respir J 2005; 26: 563-565.

5 Pride NB, Macklem PT. Lung mechanics in disease. In: Fishman AP, ed. Handbook of Physiology, Section 3, Vol III, Part 2: The Respiratory System. Bethesda, American Physiological Society, 1986; pp. 659-692.

6 Vinegar A, Sinnett EE, Leith DE. Dynamic mechanisms determine functional residual capacity in mice Mus musculus. J Appl Physiol 1979; 46: 867-871.

7 Sharp JT. The respiratory muscles in chronic obstructive pulmonary disease. Am Rev Respir Dis 1986; 134: 1089-1091.

8 Demedts M. Mechanisms and consequences of hyperinflation. Eur Respir J 1990; 3: 617-618.

9 Macklem PT. Hyperinflation. Am Rev Respir Dis 1984; 129: $1-2$.

10 Leith DE, Brown R. Human lung volumes and the mechanisms that set them. Eur Respir J 1999; 13: 468-472.

11 Cormier Y. Mechanisms of hyperinflation in asthma. Eur Respir J 1990; 3: 619-624.

12 Martin JG. Inspiratory muscle activity during induced hyperinflation. Respir Physiol 1980; 39: 303-313.

13 Cole P, Savard P, Miljeteig H, Haight JS. Resistance to respiratory airflow of the extrapulmonary airways. Laryngoscope 1993; 103: 447-450.

14 Parker CM, Voduc N, Aaron SD, Webb KA, O'Donnell DE. Physiological changes during symptom recovery from 
moderate exacerbations of COPD. Eur Respir J 2005; 26: 420-428.

15 Stevenson NJ, Walker PP, Costello RW, Calverley PM. Lung mechanics and dyspnea during exacerbations of chronic obstructive pulmonary disease. Am J Respir Crit Care Med 2005; 172: 1510-1516.

16 O'Donnell DE, Parker CM. COPD exacerbations. 3. Pathophysiology. Thorax 2006; 61: 354-361.

17 O’Donnell DE, Revill S, Webb KA. Dynamic hyperinflation and exercise intolerance in COPD. Am J Respir Crit Care Med 2001; 164: 770-777.

18 Gelb AF, Guitierrez CA, Weisman IM, Newsom R, Taylor CF, Zamel N. Simplified detection of dynamic hyperinflation. Chest 2004; 126: 1855-1860.

19 O'Donnell DE, D'Arsigny C, Webb KA. Effects of hyperoxia on ventilatory limitation during exercise in advanced chronic obstructive pulmonary disease. Am J Respir Crit Care Med 2001; 163: 892-898.

20 Stokes W. A treatise on the diagnosis and treatment of diseases of the chest. Part 1. Diseases of the lung and windpipe. London, The New Sydenham Society, 1837; pp. 168-169.

21 Sharp JT. The respiratory muscles in emphysema. Clin Chest Med 1983; 4: 421-432.

22 Sharp JT, Goldberg NB, Druz WS, Fishman HC, Danon J. Thoraco-abdominal motion in chronic obstructive lung disease. Am Rev Respir Dis 1977; 115: 47-56.

23 Simon G. Principles of Chest X-ray Diagnosis. 3rd Edn. London, Butterworths, 1971.

24 Simon G, Pride NB, Jones NL, Raimondi AC. Relation between abnormalities in the chest radiograph and changes in pulmonary function in chronic bronchitis and emphysema. Thorax 1973; 28: 15-23.

25 Burki NK, Krumpelman JL. Correlation of pulmonary function with the chest roentgenogram in chronic airway obstruction. Am Rev Respir Dis 1980; 121: 217-223.

26 Nakano Y, Muro S, Sakai H, et al. Computed tomographic measurements of airway dimensions and emphysema in smokers. Correlation with lung function. Am J Respir Crit Care Med 2000; 162: 1102-1108.

27 de Jong PA, Müller NL, Paré PD, Coxson HO. Computed tomographic imaging of the airways: relationship to structure and function. Eur Respir J 2005; 26: 140-152.

28 Pellegrino R, Viegi G, Brusasco V, et al. ATS/ERS Task Force: Standardisation of lung function testing: Interpretative strategies for lung function tests. Eur Respir J 2005; 26: 948-968.

29 Quanjer PH, Tammeling GJ, Cotes JE, Pedersen OF, Peslin R, Yernault JC. Lung volumes and forced ventilatory flows. Report Working Party Standardization of Lung Function Tests, European Community for Steel and Coal. Official Statement of the European Respiratory Society. Eur Respir J 1993; 6: Suppl. 16, 5-40.

30 Tantucci C, Duguet A, Similowski T, Zelter M, Derenne JP, Milic-Emili J. Effect of salbutamol on dynamic hyperinflation in chronic obstructive pulmonary disease patients. Eur Respir J 1998; 12: 799-804.

31 Diaz O, Villafranca C, Ghezzo H, et al. Role of inspiratory capacity on exercise tolerance in COPD patients with and without tidal expiratory flow limitations at rest. Eur Respir J 2000; 16: 269-275.
32 Casanova C, Cote C, de Torres JP, et al. Inspiratory-to-total lung capacity ratio predicts mortality in patients with chronic obstructive pulmonary disease. Am J Respir Crit Care Med 2005; 171: 591-597.

33 O'Donnell DE, Lam M, Webb KA. Measurement of symptoms, lung hyperinflation and endurance during exercise in chronic obstructive pulmonary disease. Am J Respir Crit Care Med 1998; 158: 1557-1565.

34 O'Donnell DE, He Z, Lam M, Webb K, Fluge T, Hamilton A. Reproducibility of measurements in inspiratory capacity, dyspnea intensity and exercise endurance in multicentre trials in COPD. Eur Respir J 2004; 24: 323s.

35 O'Donnell D, Flüge T, Gerken F, et al. Effects of tiotropium on lung hyperinflation, dyspnoea and exercise tolerance in COPD. Eur Respir J 2004; 23: 832-840.

36 Maltais F, Hamilton A, Marciniuk D, et al. Improvements in symptom-limited exercise performance over eight hours with once-daily Tiotropium in patients with COPD. Chest 2005; 128: 1168-1178.

37 Aliverti A, Stevenson N, Dellaca RL, Lo Mauro A, Pedotti A, Calverley PM. Regional chest wall volumes during exercise in chronic obstructive pulmonary disease. Thorax 2004; 59: 210-216.

38 Clarenbach CF, Senn O, Brack T, Kohler M, Bloch KE. Monitoring of ventilation during exercise by a portable respiratory inductive plethysmograph. Chest 2005; 128: 1282-1290.

39 Stubbing DG, Pengelly LD, Morse JLC, Jones NL. Pulmonary mechanics during exercise in subjects with chronic airflow obstruction. I Appl Physiol 1980; 49: 511-515.

40 Vogiatzis I, Georgiadou O, Golemati S, et al. Patterns of dynamic hyperinflation during exercise and recovery in patients with severe chronic obstructive pulmonary disease. Thorax 2005; 60: 723-729.

41 O'Donnell DE, Laveneziana P. The clinical importance of dynamic lung hyperinflation in COPD. COPD: Journal of Chronic Obstructive Pulmonary Disease 2006; 3: 219-232.

42 Similowski T, Yan S, Gauthier AP, Macklem PT, Bellemare F. Contractile properties of the human diaphragm during chronic hyperinflation. N Engl J Med 1991; 325: 917-923.

43 Orozco-Levi M, Gea J, Lloreta JL, et al. Subcellular adaptation of the human diaphragm in chronic obstructive pulmonary disease. Eur Respir J 1999; 13: 371-378.

44 Levine S, Kaiser L, Leferovich J, Tikunov B. Cellular adaptations in the diaphgram in chronic obstructive pulmonary disease. N Engl J Med 1997; 337: 1799-1806.

45 Mercadier JJ, Schwartz K, Schiaffino S, et al. Myosin heavy chain gene expression changes in the diaphragm of patients with chronic lung hyperinflation. Am J Physiol 1998; 274: L527-L534.

46 O'Donnell DE, Webb KA. Exercise. In: Calverley PMA, MacNee W, Pride NB, Rennard SI, eds. Chronic Obstructive Pulmonary Disease. 2nd Edn. London, Arnold, 2003; pp. 243-269.

47 O'Donnell DE, Bertley JC, Chau LK, Webb KA. Qualitative aspects of exertional breathlessness in chronic airflow limitation: pathophysiologic mechanisms. Am J Respir Crit Care Med 1997; 155: 109-115. 
48 Sinderby C, Spahija J, Beck J, et al. Diaphragm activation during exercise in chronic obstructive pulmonary disease. Am J Respir Crit Care Med 2001; 163: 1637-1641.

49 O'Donnell DE, D'Arsigny C, Fitzpatrick M, Webb KA. Exercise hypercapnia in advanced chronic obstructive pulmonary disease: the role of lung hyperinflation. Am J Respir Crit Care Med 2002; 166: 663-668.

50 Montes de Oca M, Rassulo J, Celli BR. Respiratory muscle and cardiopulmonary function during exercise in very severe COPD. Am J Respir Crit Care Med 1996; 154: 1284-1289.
51 Light RW, Mintz WM, Linden GS, Brown SE Hemodynamics of patients with severe chronic obstructive pulmonary disease during progressive upright exercise. Am Rev Respir Dis 1984; 130: 391-395.

52 Vizza CD, Lynch JP, Ochoa LL, Richardson G, Trulock EP. Right and left ventricular dysfunction in patients with severe pulmonary disease. Chest 1998; 113: 576-583.

53 O'Donnell DE, Hamilton AL, Webb KA. Sensory-mechanical relationships during high-intensity, constant-work-rate exercise in COPD. J Appl Physiol 2006; 101: 1025-1035. 